Article

\title{
Features of Ni-W Plating Film Obtained by the Jet-Flow System
}

\author{
Yuka Tsuruta ${ }^{1,2, *}$, Yasushi Umeda ${ }^{3,4}$, Hideo Honma $^{3}$, Osamu Takai ${ }^{3}$ and Katsuhiko Tashiro ${ }^{3,4}$ \\ 1 Graduate School of Engineering, Kanto Gakuin University, Yokohama 236-8501, Japan \\ 2 Ebina Denka Kogyo Co., Ltd. Ota, Tokyo 144-0033, Japan \\ 3 Materials and Surface Engineering Research Institute, Kanto Gakuin University, Odawara 250-0042, Japan; \\ umeda@kanto-gakuin.ac.jp (Y.U.); honma@kanto-gakuin.ac.jp (H.H.); takai@kanto-gakuin.ac.jp (O.T.); \\ r051048@kanto-gakuin.ac.jp (K.T.) \\ 4 Research Advancement and Management Organization, Kanto Gakuin University, Yokohama 236-8501, Japan \\ * Correspondence: kobayashi-y@ebinadk.com; Tel.: +81-3-3742-0107
}

check for updates

Citation: Tsuruta, Y.; Umeda, Y.;

Honma, H.; Takai, O.; Tashiro, K. Features of Ni-W Plating Film Obtained by the Jet-Flow System. AppliedChem 2021, 1, 41-49. https://doi.org/10.3390/ appliedchem1010004

Academic Editor: Svetlozar Velizarov

Received: 21 July 2021

Accepted: 18 August 2021

Published: 20 August 2021

Publisher's Note: MDPI stays neutral with regard to jurisdictional claims in published maps and institutional affiliations.

Copyright: (c) 2021 by the authors. Licensee MDPI, Basel, Switzerland. This article is an open access article distributed under the terms and conditions of the Creative Commons Attribution (CC BY) license (https:// creativecommons.org/licenses/by/ $4.0 /)$.

\begin{abstract}
Chromium plating has excellent corrosion resistance and is widely used in industry. However, it also has a high environmental load. As an alternative, electric Ni-W plating is attracting attention. However, it is not widely used because the stress is high and the film is prone to cracks. Furthermore, although it is necessary to thicken the film to improve the corrosion resistance, there are also problems that the current efficiency is low and the plating time is long. Therefore, we investigate a film with high corrosion resistance by using the jet-flow plating method that enables plating at a high current density. Our results show that the jet-flow plating enables plating of $50 \mu \mathrm{m}$, and high corrosion resistance is obtained by randomly generating fine cracks in the film at $20 \mathrm{~A} \cdot \mathrm{dm}^{-2}$. We also found that the stress changed depending on the current density and shape of the crack also changed.
\end{abstract}

Keywords: electro Ni-W plating; jet-flow device; high current density; corrosion resistance; micro cracks

\section{Introduction}

In general, chromium plating has excellent properties, such as corrosion resistance, acid resistance, and high hardness. It is widely used in modern industries, such as parts, engines, and dies, taking advantage of its hardness and wear resistance [1,2]. However, the environmental load of hexavalent chromium used for chrome plating is high, and may become unusable, due to environmental regulations [3-6].

Alternative research on chromium plating has been widely conducted, $\mathrm{Ni}-\mathrm{W}$ is attracting attention in addition to WC film formation by sputtering, and trivalent chrome plating [7-9]. Tungsten is a metal with high hardness and high wear resistance [10]. While it does not precipitate as a plating film by itself, it has the property of induced co-deposit with iron groups, such as nickel [11]. It has already been reported that Ni-W plating has high wear resistance and hardness $[12,13]$. However, Ni-W plating film has many problems, such as cracks easily, low current efficiency, and high internal stress [14,15], and has not been widely put into practical use. Even if the corrosion resistance of the Ni-W plating film is high, it is necessary to be careful because corrosion factors, such as gas and plating solution that enter from cracks, corrode the base of the plating film and deteriorate the performance of the film.

We investigated the relationship between the structure of the Ni-W plating film and corrosion resistance. As a means for improving the corrosion resistance of the film, there are methods, such as multi-layering the films having different structures, increasing the W content, and combining nanoparticles [16-18]. However, considering the long-term reliability of the product, thickening the film is one of the most effective means. On the other hand, it takes a long time to make a thick film and can be one of the barriers to industrialization [19]. Although the speed of electroplating can be achieved by increasing the current density, in the conventional plating equipment, the supply of metal ions to the cathode may be delayed, and abnormal precipitation may occur [20]. We have succeeded 
in producing a good plating film even at $50 \mathrm{~A} \cdot \mathrm{dm}^{-2}$ in electrolytic copper plating using the jet-flow electroplating device that can supply stable metal ions even under high current density [21]. We tried to thicken the Ni-W plating using this device and evaluated its corrosion resistance.

\section{Materials and Methods}

\subsection{Plating Conditions}

Table 1 shows the basic composition and conditions of the plating bath. Nickel sulfate and sodium tungstate were used as metal salts, and triammonium citrate was used as a complexing agent [22]. All chemicals are special grade chemicals. The concentration of the complexing agent was $0.8 \mathrm{~mol} \cdot \mathrm{dm}^{-3}$, which was equivalent to the total number of moles of the metal salt, and the bath $\mathrm{pH}$ was adjusted to 6.0 with dilute sulfuric acid and an aqueous solution of sodium hydroxide. The temperature of the plating bath is $40^{\circ} \mathrm{C}$. Platinum-coated titanium was used for the anode. A copper plate (Halcel plate, Yamamoto-MS) was used as the test substrate, and after adjusting the plating area to $10 \mathrm{~mm} \times 20 \mathrm{~mm}$, the protective sheet on the effective surface was peeled off, and plating was performed immediately.

Table 1. Plating bath composition and conditions.

\begin{tabular}{ccc}
\hline \multirow{3}{*}{ Plating bath composition } & $\mathrm{Ni}_{2} \mathrm{SO}_{4} \cdot 6 \mathrm{H}_{2} \mathrm{O}$ & $0.4 \mathrm{~mol} \cdot \mathrm{dm}^{-3}$ \\
& $\mathrm{NaWO}_{4} \cdot 2 \mathrm{H}_{2} \mathrm{O}$ & $0.4 \mathrm{~mol} \cdot \mathrm{dm}^{-3}$ \\
& $\left(\mathrm{NH}_{4}\right)_{3} \mathrm{C}_{6} \mathrm{H}_{5} \mathrm{O}$ & $0.8 \mathrm{~mol} \cdot \mathrm{dm}^{-3}$ \\
\hline \multirow{3}{*}{ Operating condition } & Substrate & $\mathrm{Cu}$ \\
& Plating area & $10 \mathrm{~mm} \times 20 \mathrm{~mm}$ \\
& pH & 6.0 \\
\hline
\end{tabular}

\subsection{Normal Plating and JET-Flow Plating}

Experiments were carried out by the normal plating and the jet-flow plating. For the normal plating, a $500 \mathrm{~mL}$ plating bath was placed in a $500 \mathrm{~mL}$ beaker, and stirred with a magnetic stirrer. For the jet-flow plating, we used the equipment (Yamamoto-MS) shown in Figure 1.
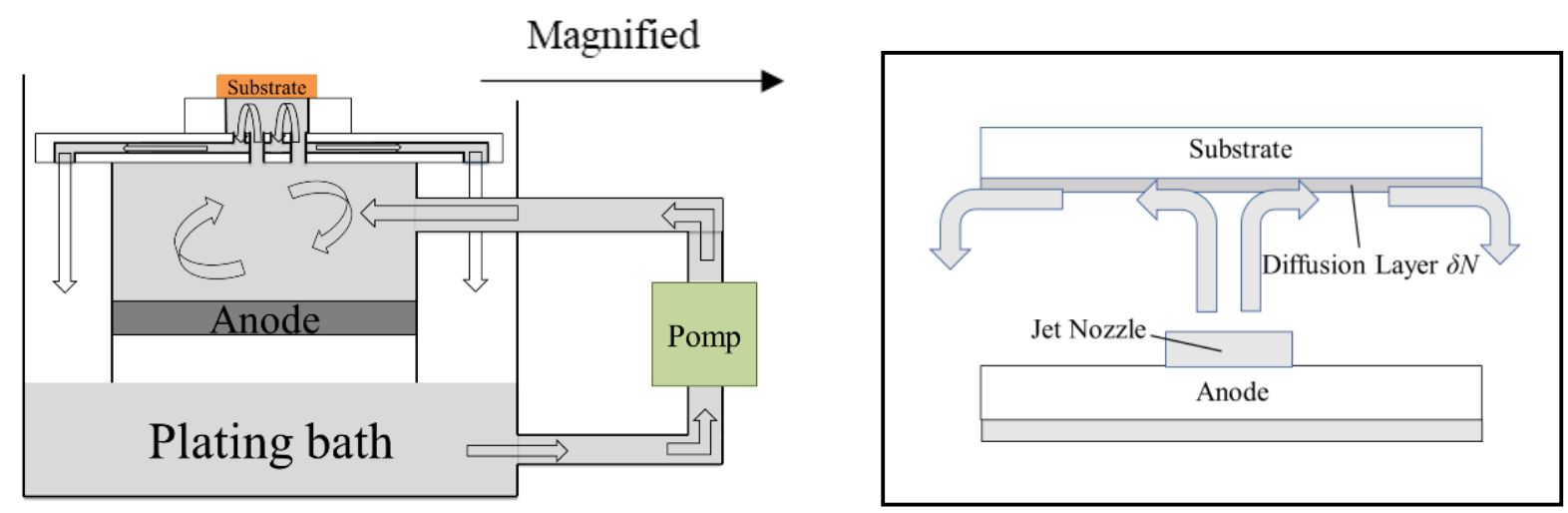

Figure 1. Schematic diagram of the jet-flow plating equipment. The magnified view is a schematic view of the diffusion layer. The strong jet makes the diffusion layer thin and enables plating under high current densities.

The diffusion limit current (faradaic current density) $i\left(\mathrm{~A} \cdot \mathrm{cm}^{-2}\right)$ is given as Equation (1).

$$
i=z F D_{o} C_{o} / \delta_{N}
$$


where $z$ is the electron valence, $\boldsymbol{F}$ is the Faraday constant, $\boldsymbol{D}_{\boldsymbol{o}}$ is the diffusion coefficient $\left(\mathrm{cm}^{2} \cdot \mathrm{s}^{-1}\right)$ of the plating bath (reactant $\left.O x\right), C_{o}$ is the concentration of the plating bath offshore $\left(\mathrm{mol} \cdot \mathrm{dm}^{-3}\right)$, and $\delta_{N}$ are the thickness of the Nernst diffusion layer [23].

That is, since it is proportional to the plating bath concentration and inversely proportional to the thickness of the diffusion layer, it is important to thin the diffusion layer. This device sets the surface to be plated downward and injects the plating solution from below. The structure can constantly supply a new plating solution to the reaction interface. It effectively thins the diffusion layer and has succeeded in plating with a current density of $50 \mathrm{~A} \cdot \mathrm{dm}^{-2}$ in electrolytic copper plating [21]. In this study, the jet-flow plating was performed with a liquid flow of $7 \mathrm{dm}^{3} \cdot \mathrm{min}^{-1}$.

\subsection{Evaluation of Plating Film}

\subsubsection{Alloy Composition Analysis}

The film composition was determined by ICP (ICPW-9820, Shimadzu Corporation, Kyoto, Japan). After dissolving the $2 \mu \mathrm{m}$ plated film with aqua regia, the alloy composition of $\mathrm{Ni}$ and $\mathrm{W}$ was analyzed and determined at an exposure time of $30 \mathrm{~s}$, observation wavelengths of $207.911 \mathrm{~nm}$ for $\mathrm{Ni}$, and $231.604 \mathrm{~nm}$ for $\mathrm{W}$.

\subsubsection{Current Density}

The weight difference between the substrates before and after plating was measured with the electronic scale (GR-202, AND, Tokyo, Japan), and the film thickness was calculated from the alloy composition of Section 2.3.1. The current efficiency was calculated by comparing the obtained film thickness with the calculated $100 \%$ electrodeposition. Plating was applied three times at each current density, and the value of the average film thickness was used.

\subsubsection{Corrosion Resistance Test}

Chromium plating for functionality is plated at 5 to $500 \mu \mathrm{m}$ depending on the application and purpose. Although the thicker the film thickness, the better the corrosion resistance is expected, it is generally used in industry at 30 to $50 \mu \mathrm{m}$ [24]. Therefore, in this study, the evaluation was performed at $50 \mu \mathrm{m}$. The corrosion resistance of the $50 \mu \mathrm{m}$ film was tested according to Annex 1 of JIS H8620. Nitric acid was placed on the bottom of the desiccator, and a sample masked with tape other than the plated surface was left at $24{ }^{\circ} \mathrm{C}$ for $24 \mathrm{~h}$ in that atmosphere. Then, the degree of corrosion was visually observed. The case when there was no change, when partial corrosion was observed, and when corrosion occurred on the entire surface, it was judged as A, B, and C, respectively.

\subsubsection{Observation of Plating Film Surface and Cross Section}

The $50 \mu \mathrm{m}$ plated film was observed with a nano-search microscope (OLS4500, Olympus, Tokyo, Japan) $2000 \times$. For cross section view, polished with a cross section polisher (SM09010, JEOL Ltd., Tokyo, Japan) for $10 \mathrm{~h}$, and then the cross section was observed using FE-SEM (JSM-7000F, JEOL Ltd., Tokyo, Japan) at the acceleration voltage of $5 \mathrm{kV}$.

\subsubsection{Number of Cracks in the Plating Film}

The number of cracks on the surface of the film was counted by the following method. A straight line of $130 \mu \mathrm{m}$ was arbitrarily drawn in the field of view observed with a nanosearch microscope (OLS4500, Olympus, Tokyo, Japan) 2000×, cracks intersecting the line were counted, and converted to the number of intersections per $1 \mathrm{~mm}$. The number of fields of view was 2, and cracks were counted with three lines in each field of view, and the average value was adopted [15]. Figure 2 shows an example of counting cracks. 


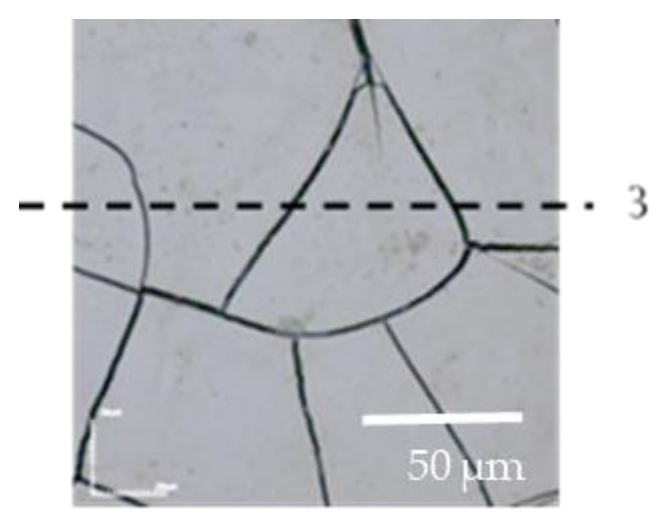

Figure 2. An example of counting cracks. Draw a straight line in the field of view and count the cracks that intersect that line. In this example, there are three cracks in the field of view. One side of this field of view corresponds to $130 \mu \mathrm{m}$, and the number of cracks converted to the number of cracks per $1 \mathrm{~mm}$ is reflected in the result.

\subsubsection{The Internal Stress in the Normal Plating}

The film stress of normal plating was obtained by plating $1 \mu \mathrm{m}$ on the plating internal stress measurement test piece (here in after referred to as a test strip, Specialty Testing, and Development Company). The test strip is a $100 \mu \mathrm{m}$ thick copper alloy C-1940 (Cu-2.4 $\mathrm{Fe}-1.0 \mathrm{Zn}$; mass\%), and the open legs are masked on different sides and open according to the internal stress generated by plating. The magnitude of internal stress was calculated from the degree of leg opening. When the plated surface was opened inward, it was judged as the compressive stress, and when the masked surface was opened inward, it was judged as the tensile stress $[25,26]$.

\section{Results and Discussion}

\subsection{Alloy Composition Analysis}

Figure 3 shows the tungsten content in the plating film when the current density is changed by eight levels from 5 to $50 \mathrm{~A} \cdot \mathrm{dm}^{-2}$ in the normal plating and the jet-flow plating. As a result, no correlation was observed between normal plating and the jet-flow plating, and the composition of the Ni-W plating film remained within 10 to $25 \mathrm{wt} \%$ as $\mathrm{W}$.

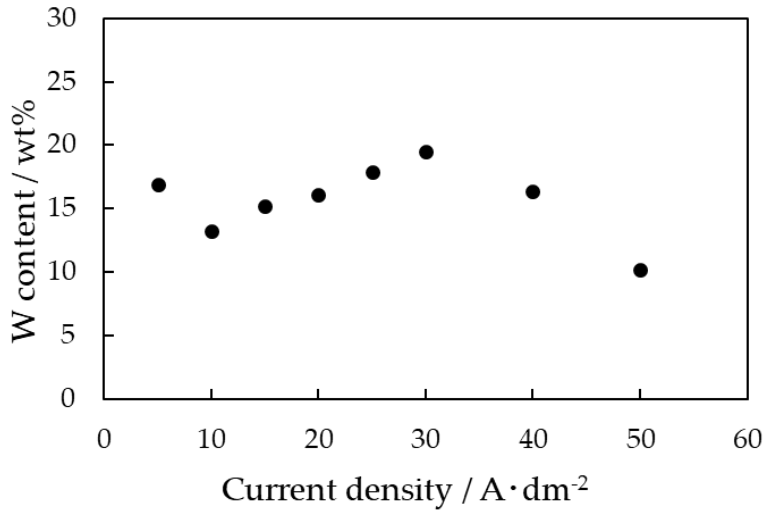

(a) Normal plating

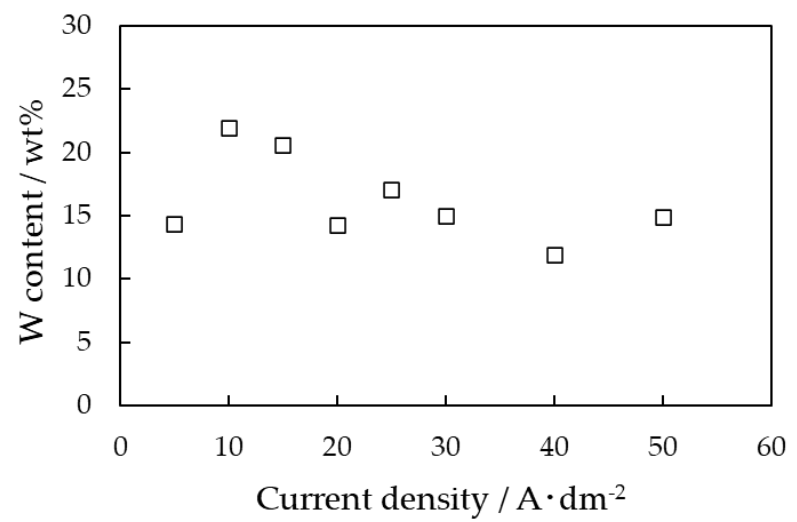

(b) Jet-flow plating

Figure 3. Relationship between current density and $\mathrm{W}$ content in deposited film on (a) the normal plating and (b) the jet-flow plating. 
No significant relationship between the current density and the alloy composition has been reported [12], and no clear effect was observed on the alloy composition even when the jet plating apparatus used in this study was used. Although the ratio of tungsten in the plating film depends on the composition of the plating bath and the $\mathrm{pH}$, it is assumed that the ratio of the alloy is not affected because the current density and the plating method do not affect the eutectoid and potential of tungsten.

\subsection{Thickening of the Plating Film}

Figure 4 shows the visual appearance of the $5 \mathrm{~A} \cdot \mathrm{dm}^{-2}, 20 \mu \mathrm{m}$ plated film by the normal plating and the jet-flow plating. The film peeled because of internal stress on the normal plating; however, no peeling on the jet-flow plating was observed visually. In addition, when plating was performed with a current density of 5 to $50 \mathrm{~A} \cdot \mathrm{dm}^{-2}$, all of the normal plating peeled off to various degrees. On the other hand, in the jet-flow plating, there was no film peeling under all conditions, and a thickness of $50 \mu \mathrm{m}$ was possible. It is assumed that this is related to the time required for the hydrogen gas generated by the plating reaction to separate from the substrate surface. In the normal plating, hydrogen gas tends to stay on the reaction surface, and the growth of the plating film at the gasadhered portion is hindered. As a result, the plating growth became non-uniform, which is considered to have led to film peeling. On the other hand, in the jet-flow plating, it is considered that even if hydrogen gas is generated, the gas is quickly released by the jet-flow, and a uniform plating surface can be formed.

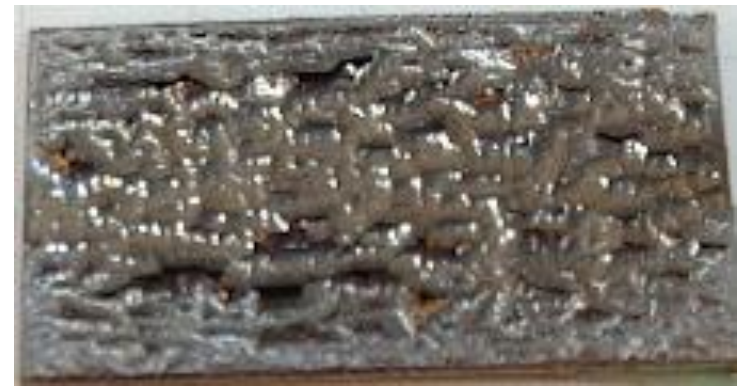

(a) Normal plating

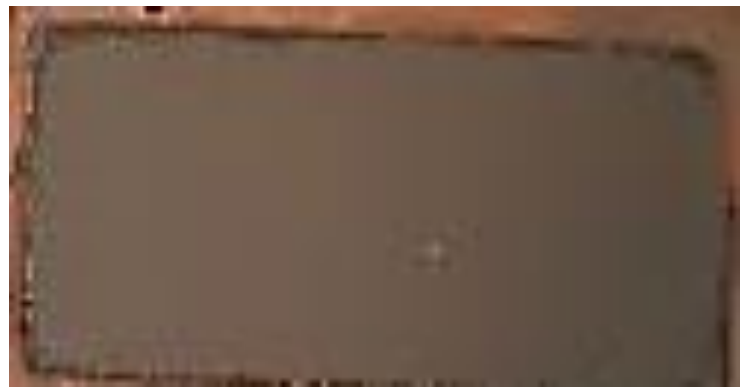

(b) Jet-Flow plating

Figure 4. Visually images of the plating film surface $(20 \mu \mathrm{m})$ obtained from (a) normal plating and (b) jet-flow plating (taken by digital camera). While the plating film was peeled off in the normal plating, plating was possible in the jet-flow plating.

\subsection{Current Efficiency in the Jet-Flow Plating}

With the normal plating, cracks and film peeling occurred at $5 \mu \mathrm{m}$ or less; therefore, current efficiency could not be measured. Figure 5 shows the current efficiency of $50 \mu \mathrm{m}$ film by the jet-flow plating. The current efficiency at 20 to $50 \mathrm{~A} \cdot \mathrm{dm}^{-2}$ was higher than the current efficiency at 5 to $15 \mathrm{~A} \cdot \mathrm{dm}^{-2}$, and the current density tended not to change significantly at a current density of $20 \mathrm{~A} \cdot \mathrm{dm}^{-2}$ or higher. It is assumed to be because the amount of hydrogen gas generated increases at high current densities, which further promotes gas release from the reaction surface. It took only $13 \mathrm{~min}$ to deposit $50 \mu \mathrm{m}$ with a current density of $50 \mathrm{~A} \cdot \mathrm{dm}^{-2}$.

Below $20 \mathrm{~A} \cdot \mathrm{dm}^{-2}$, the lower the current density, the lower the current efficiency tends to be. 


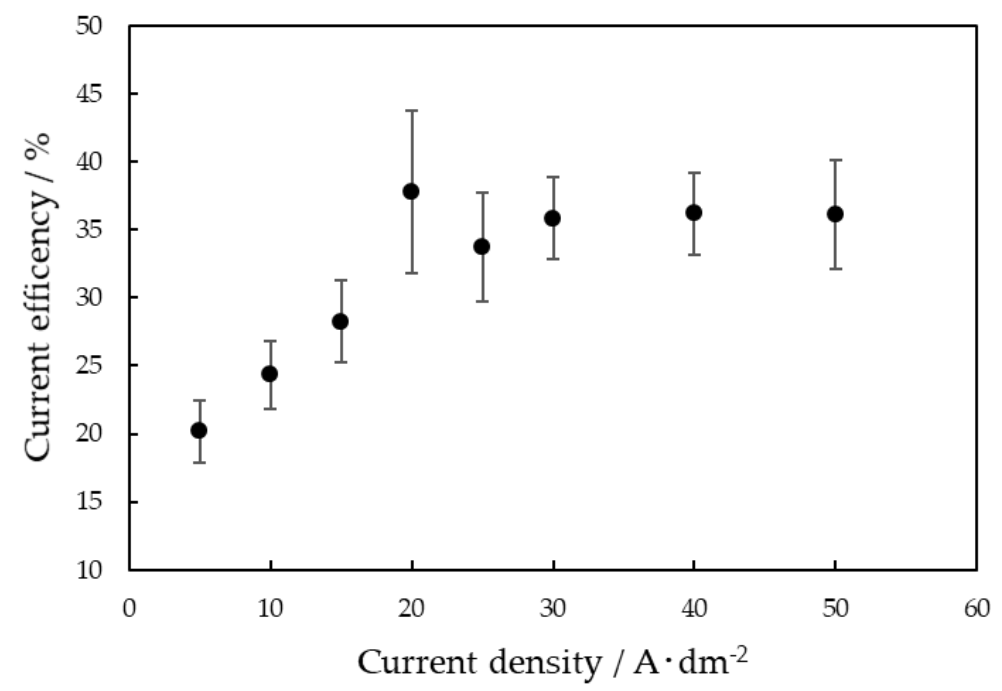

Figure 5. Relationship between current density and current efficiency.

\subsection{Relationship between Corrosion Resistance, Number of Cracks, and Stress}

Table 2 shows the corrosion resistance test results of the film plated with $50 \mu \mathrm{m}$ by the jet-flow plating. As a result, it was found that there is a difference in corrosion resistance depending on the current density. At $20 \mathrm{~A} \cdot \mathrm{dm}^{-2}$, no patina derived from copper, which is the substrate, is observed. It shows excellent corrosion resistance. In the other samples, patina occurred in part or in whole. Even in the sample in which patina was observed, the $\mathrm{Ni}-\mathrm{W}$ film itself was not dissolved when washed with deionized water and dried, and the appearance was close to that before the corrosion resistance test. Although the corrosion resistance of Ni-W can withstand an environment of $24 \mathrm{~h}$ under a nitric acid atmosphere, it is assumed that the substrate corrosion occurred, due to film defects.

Table 2. Each current density and its corrosion resistance on jet-flow plating $(50 \mu \mathrm{m})$. " $\mathrm{A}$ " had the highest corrosion resistance, and no patina derived from copper, which is the base material, was found. In " $\mathrm{B}$ ", patina is generated on a part of the board. In " $\mathrm{C}$ ", patina occurred on the entire surface.

\begin{tabular}{ccccccccc}
\hline $\begin{array}{c}\text { Current density } \\
\left(\mathrm{A} \cdot \mathrm{dm}^{-2}\right)\end{array}$ & 5 & 10 & 15 & 20 & 25 & 30 & 40 & 50 \\
\hline $\begin{array}{c}\text { Corrosion level } \\
(-)\end{array}$ & C & C & B & A & B & C & C & C \\
\hline
\end{tabular}

Figure 6 shows the surface and the cross section of the film plated with 5, 20, and $50 \mathrm{~A} \cdot \mathrm{dm}^{-2}$ at $50 \mu \mathrm{m}$. From the surface, it was found that in $5 \mathrm{~A} \cdot \mathrm{dm}^{-2}$, there were many smooth parts, and cracks were linearly formed. On the other hand, at 20 and $50 \mathrm{~A} \cdot \mathrm{dm}^{-2}$, the surface was uneven, and cracks were also generated along with the unevenness. At high current densities, it is assumed that the amount of gas generated per unit time is large, and the film grows before the gas is completely removed from the reaction surface, therefore the surface had become uneven.

From the cross section, in both 5 and $50 \mathrm{~A} \cdot \mathrm{dm}^{-2}$, large cracks penetrating the substrate surface were observed. On the other hand, at $20 \mathrm{~A} \cdot \mathrm{dm}^{-2}$, it was observed that fine cracks were randomly formed. It is assumed that the random fine cracks disperse the origin of corrosion, therefore high corrosion resistance was obtained [27,28]. As shown in Figure 3, since there is no difference in the tungsten content (about $15 \mathrm{wt} \%$ ) depending on the current density, it can be judged that there is no correlation between the crack-morphologies and the tungsten content. 


\section{Surface}

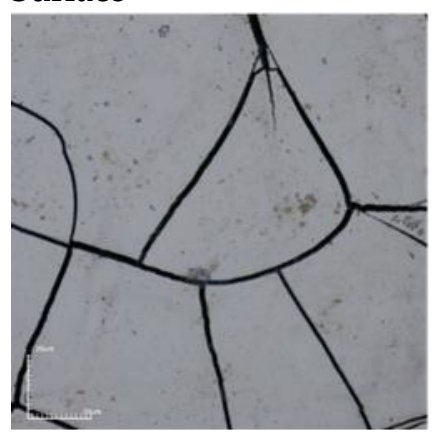

(a) Surface $5 \mathrm{~A} \cdot \mathrm{dm}^{-2}$ Cross section

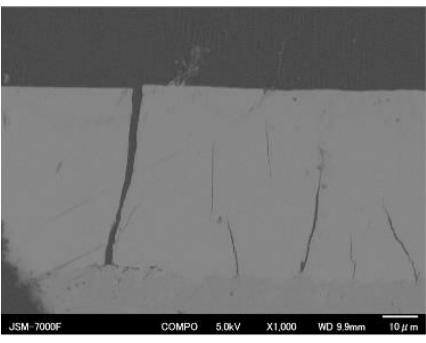

(d) Cross section $5 \mathrm{~A} \cdot \mathrm{dm}^{-2}$

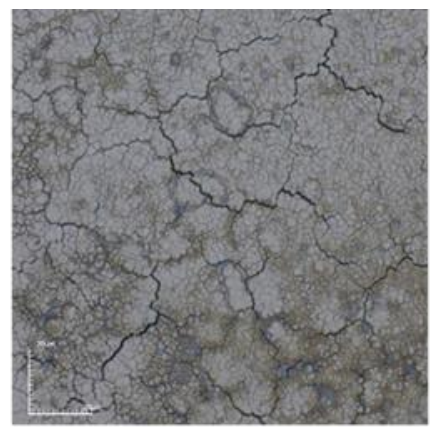

(b) Surface $20 \mathrm{~A} \cdot \mathrm{dm}^{-2}$

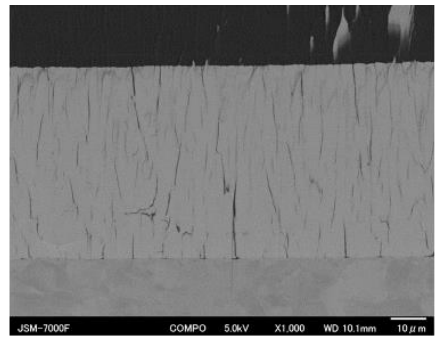

(e) Cross section $20 \mathrm{~A} \cdot \mathrm{dm}^{-2}$

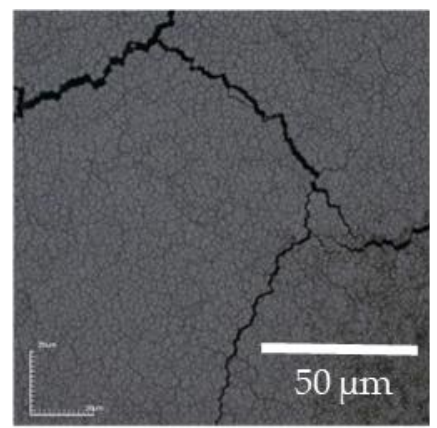

(c) Surface $50 \mathrm{~A} \cdot \mathrm{dm}^{-2}$

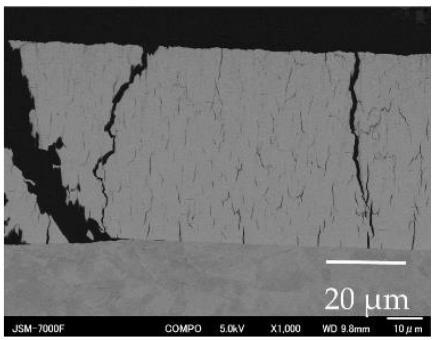

(f) Cross section $50 \mathrm{~A} \cdot \mathrm{dm}^{-2}$

Figure 6. Surface view by nano-search microscope (above) and cross section view by FE-SEM (below). In both 5 and $50 \mathrm{~A} \cdot \mathrm{dm}^{-2}$, large cracks penetrating the substrate surface were observed. On the other hand, at $20 \mathrm{~A} \cdot \mathrm{dm}^{-2}$, it was observed that fine cracks were randomly formed. (a) Surface $5 \mathrm{~A} \cdot \mathrm{dm}^{-2}$, (b) Surface $20 \mathrm{~A} \cdot \mathrm{dm}^{-2}$, (c) Surface $50 \mathrm{~A} \cdot \mathrm{dm}{ }^{-2}$, (d) Cross section $5 \mathrm{~A} \cdot \mathrm{dm}^{-2}$, (e) Cross section $20 \mathrm{~A} \cdot \mathrm{dm}^{-2}$, (f) Cross section $50 \mathrm{~A} \cdot \mathrm{dm}^{-2}$.

Figure 7 shows the results of the number of cracks obtained by averaging three lines for each of the two fields of view.

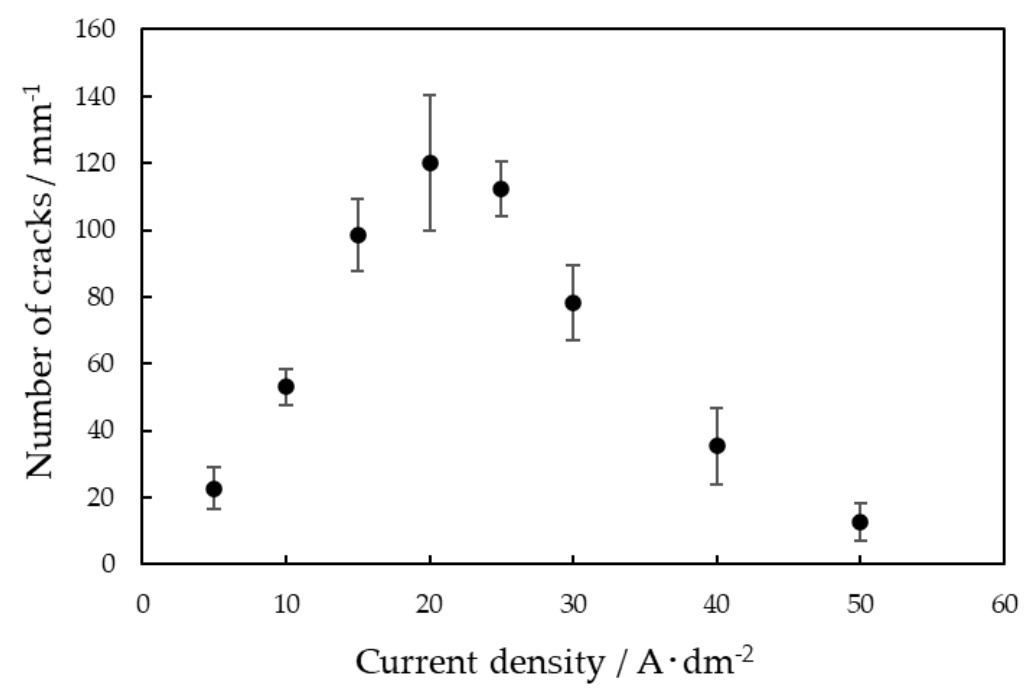

Figure 7. Relationship between current density and number of cracks. The number of cracks was maximum at $20-25 \mathrm{~A} \cdot \mathrm{dm}^{-2}$.

As a result, the number of cracks generated on the surface was maximum at 20-25 A $\cdot \mathrm{dm}^{-2}$, and then tended to decrease. From the results in Table 2, it was found that 15 to $25 \mathrm{~A} \cdot \mathrm{dm}^{-2}$, which showed good corrosion resistance, had more surface fine cracks than the conditions with low corrosion resistance. It is assumed that many surface fine cracks suppressed the generation of large cracks reaching the substrate. 
Figure 8 shows the film stress measured by normal plating. As a result, it was found that the stress around 20-25 A. $\mathrm{dm}^{-2}$, which had many fine cracks in Figure 7, was high Due to the high stress, many fine cracks were formed at the initial stage of film formation, and the cracks randomly occurred. Therefore, it is assumed that large cracks penetrating the substrate were avoided, due to the film thickening [29]. On the other hand, if the film stress is low, cracks do not generate at the initial stage, and the large cracks generate after the film becomes thick; therefore, it is assumed that the cracks penetrate the substrate.

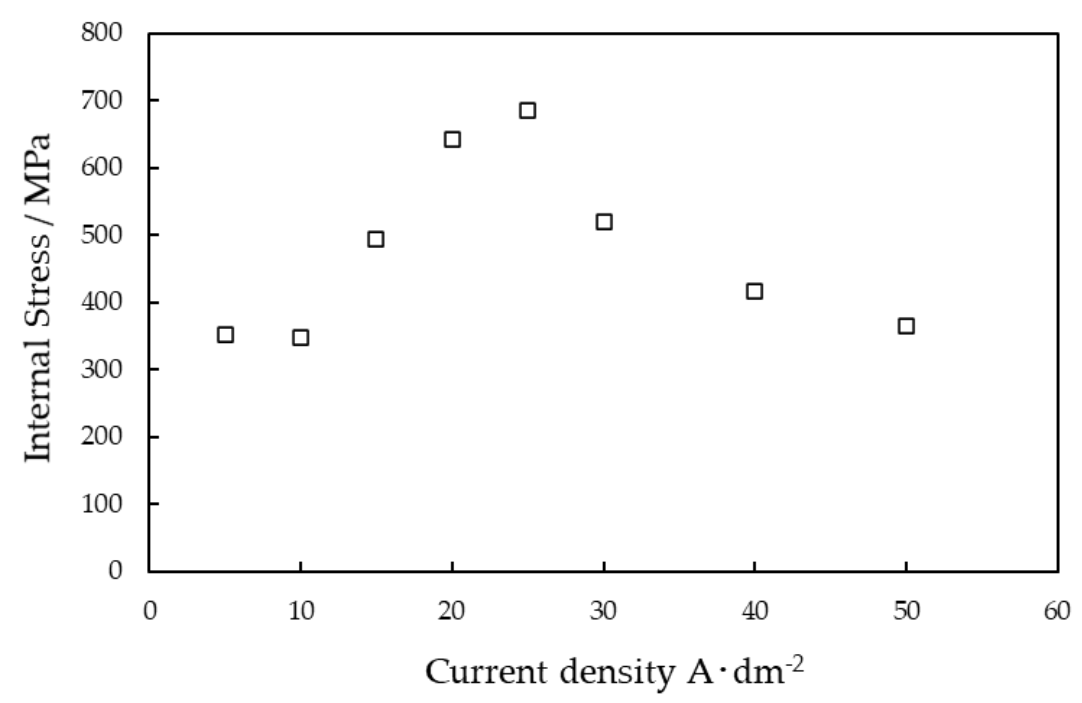

Figure 8. Relationship between current density and film stress in the normal plating. The stress tended to be high in the vicinity of $20-25 \mathrm{~A} \cdot \mathrm{dm}^{-2}$, where the number of cracks was large in jet plating.

\section{Conclusions}

As a result of performing electric Ni-W plating by the normal plating and the jet-flow plating, the following was found:

1. In the normal plating, when $20 \mu \mathrm{m}$ plating was performed in the current density range of 5 to $50 \mathrm{~A} \cdot \mathrm{dm}^{-2}$, film peeling occurred in all cases. On the other hand, the jet-flow plating did not cause film peeling, and a film formation of $50 \mu \mathrm{m}$ was possible.

2. When the corrosion resistance was tested in the range of 5 to $50 \mathrm{~A} \cdot \mathrm{dm}^{-2}$, the fine cracks were randomly generated at $20 \mathrm{~A} \cdot \mathrm{dm}^{-2}$, showing the excellent corrosion resistance.

3. When the stress of normal plating was measured, it was all tensile stress. The higher the current density, the higher the stress. However, at $25 \mathrm{~A} \cdot \mathrm{dm}^{-2}$ and above, it decreases as the current density increased. This had a correlation with the number of the surface fine cracks in the film plated with $50 \mu \mathrm{m}$ by the jet-flow plating. It was found that the higher the stress, the finer the cracks on the surface of the plating film, the larger the number, and the more randomly generated, which is a factor for improving the corrosion resistance.

Author Contributions: Conceptualization, Y.T. and K.T.; methodology, Y.T. and Y.U.; validation, Y.T.; investigation, Y.T.; resources, Y.U.; writing—original draft preparation, Y.T.; writing-review and editing, Y.T. and K.T.; supervision, K.T., H.H. and O.T.; project administration, K.T., H.H. and O.T. All authors have read and agreed to the published version of the manuscript.

Funding: This research received no external funding.

Institutional Review Board Statement: Not applicable.

Informed Consent Statement: Not applicable.

Conflicts of Interest: The authors declare no conflict of interest. 


\section{References}

1. Kunieda, N. Hexavealent Chrome Alternative Treatment Technology Trend on Automobile. J. Surf. Finish. Soc. Jpn. 2003, 54, 512-519. [CrossRef]

2. Bessho, T. The Trend of Plating on Plastics for Automobile Parts. J. Surf. Finish. Soc. Jpn. 2008, 59, 305-309. [CrossRef]

3. Hoshino, S. Development of Chronium Plating and Environmental Problems. J. Surf. Finish. Soc. Jpn. 2005, 56, 302-307. [CrossRef]

4. Barnhart, J. Chromium chemistry and implications for environmental fate and toxicity. Soil Sediment Contam. Int. J. 1997, 6, 561-568. [CrossRef]

5. Kimbrough, D.E.; Cohen, Y.; Winer, A.M.; Creelman, L.; Mabuni, C. A Critical Assessment of Chromium in the Environment. Crit. Rev. Environ. Sci. Technol. 1999, 29, 1-46. [CrossRef]

6. Losi, M.E.; Amrhein, C.; Frankenberger, W.T. Environmental Biochemistry of Chromium. Rev. Environ. Contam. Toxicol. 1994, 136, 91-121. [CrossRef] [PubMed]

7. Nouvellon, C.; Belchi, R.; Libralesso, L.; Douhéret, O.; Lazzaroni, R.; Snyders, R.; Thiry, D. WC/C:H films synthesized by an hybrid reactive magnetron sputtering/Plasma Enhanced Chemical Vapor Deposition process: An alternative to Cr (VI) based hard chromium plating. Thin Solid Films 2017, 630, 79-85. [CrossRef]

8. Giovanardi, R.; Orlando, G. Chromium electrodeposition from Cr(III) aqueous solutions. Surf. Coat. Technol. 2011, 205, 3947-3955. [CrossRef]

9. Onodera, H. Current Status of Trivalent Chromium Plating and Its Overseas Trends. J. Surf. Finish. Soc. Jpn. 2018, 69, 234-236. [CrossRef]

10. Sohma, H. Tungusten. J. Imaging Soc. Jpn. 1987, 26, 179-183. [CrossRef]

11. Akiyama, T.; Fukushima, H.; Higashi, K. Mechanism of Abnormal Type Alloy Deposition. Tetsu Hagane 1986, 72, 918-923. [CrossRef]

12. Hayata, S.; Oue, S.; Takahashi, T.; Nakano, H. Effect of Initial Ni Plating on the Structure and Hardness of Electrodeposited Ni-W Alloys with and without Annealing. Tetsu Hagane 2015, 101, 590-597. [CrossRef]

13. Kirihara, S.; Umeda, Y.; Tashiro, K.; Honma, H.; Takai, O. Development of Ni-W alloy plating as a substitution of hard chromium plating. Trans. Mater. Res. Soc. Jpn. 2016, 41, 35-39. [CrossRef]

14. Omi, T.; Nakamura, M.; Yamamoto, H. W-enrichment of electroplated Ni-W alloy films and film properties. J. Met. Finish. Soc. Jpn. 1988, 39, 809-812. [CrossRef]

15. Ishii, K.; Takayama, T.; Doi, T.; Kimoto, M.; Hayashi, H.; Kishimoto, A. Influence of Internal Stress on Plating Crack in Ni-W Alloy Electroplating. J. Surf. Finish. Soc. Jpn. 2014, 65, 391-395. [CrossRef]

16. Raveendran, M.N.; Hegde, A.C. Electrodeposition of multilayer NiW alloy coating for improved anticorrosion performance. Bull. Mater. Sci. 2021, 44, 1-11. [CrossRef]

17. $\mathrm{Hu}, \mathrm{Y}$. Study on Mechanical and Anticorrosion Performance of NiW Alloy Coatings Prepared by Induced Codeposition. Int. J. Electrochem. Sci. 2019, 14, 1649-1657. [CrossRef]

18. He, T.; He, Y.; Li, H.; Su, Z.; Fan, Y.; He, Z. Fabrication of Ni-W-B4C composite coatings and evaluation of its micro-hardness and corrosion resistance properties. Ceram. Int. 2018, 44, 9188-9193. [CrossRef]

19. Omi, T.; Nishido, K.; Matsumoto, H.; Yamamoto, H. Composition, current efficiency and film properties of Ni-W alloys electroplated from a citrate bath of pH6. J. Surf. Finish. Soc. Jpn. 1989, 40, 1287-1292. [CrossRef]

20. Nishihama, Y. Influence of Basic Component of plating Bath. Electrolytic Copper Plating. J. Surf. Finish. Soc. Jpn. 1999, 50, 135-139. [CrossRef]

21. Suzuki, Y.; Miyashita, Y.; Umeda, Y.; Cordonier, C.E.J.; Honma, H.; Takai, O.; Noh, J.-H. Characteristics of High-Speed Copper Plating Films Using a Jet Flow Device. J. Mater. Sci. Eng. A 2019, 9, 91-97. [CrossRef]

22. Matsuda, K.; Noguchi, H. Formation of Were-resistant Deposit by Electro Ni-W Alloy Platinh. Rep. Ind. Res. Inst. Aichi 2003, 12, 40-43.

23. Konishi, S.; Kato, S.; Goto, S.; Itabashi, S. Cathodic Limiting Current Densities in Copper Plating from Copper Sulfate and Copper Flioborate Baths, and the Diffusion Coefficients on the Salts. J. Surf. Finish. Soc. Jpn. 1979, 30, 402-406. [CrossRef]

24. Hoshino, S. Improvement of Corrosion Resisance of Hard Chromium Plated Articles. Zair. Kankyo 1995, 44, 192. [CrossRef]

25. Miyama, K.; Yoshida, K.; Saitou, S.; Takashima, T. Effects of Internal Stress of Electroless Nickel Plating on Solder Joining Strength. J. Jpn. Inst. Electron. Packag. 2015, 18, 253-260. [CrossRef]

26. Oyamada, K.; Yamamoto, W. Measurements of Internal Stresses in Electrodeposits. J. Surf. Finish. Soc. Jpn. 2007, 58, $213-218$. [CrossRef]

27. Hori, R. Micro Crack Chromium Plating. J. Surf. Finish. Soc. Jpn. 1969, 16, 15-21. [CrossRef]

28. Hayashi, T. Corrosion Resistance of Electroplated Coatings. J. Surf. Finish. Soc. Jpn. 1980, 31, 635-643. [CrossRef]

29. Kobayashi, Y. Crack Free Chromium Plating. J. Surf. Finish. Soc. Jpn. 2014, 65, 162-166. [CrossRef] 